\title{
COMPARATIVE STUDY OF CT AND MRI IN EVALUATION OF SUPRAHYOID NECK MASSES
}

\author{
Vidya Rani K1, Jeevan A. Vernekar², Sachin Shashikant Amate ${ }^{3}$
}

${ }_{1}^{1}$ Postgraduate Student, Department of Radiology, Goa Medical College, Bambolim, Goa.

2Professor and HOD, Department of Radiology, Goa Medical College, Bambolim, Goa.

${ }^{3}$ Postgraduate Student, Department of Radiology, Goa Medical College, Bambolim, Goa.

\begin{abstract}
BACKGROUND

Suprahyoid neck encompasses the deep spaces between the base of skull and hyoid bone. The masses in the neck show a wide range of origin and can be congenital or acquired, inflammatory, vascular or neoplastic.

Aim of the study is to compare the contributions of the two imaging modalities, viz. CT and MRI in the evaluation of suprahyoid neck masses and come to a conclusion regarding the added advantage of one over the other.

Study design, cross-sectional analysis was carried out on hundred cases in Department of Radiology, Goa Medical College and Hospital from October 2013 to October 2015.
\end{abstract}

\section{MATERIALS AND METHODS}

For CT imaging, Siemens definition AS 128 slice CT scanner was used. For MR imaging, Siemens Magnetom Avanto 1.5 T was used. Statistical analysis was done using odds ratio and Kappa coefficient.

\section{RESULTS}

In the analysis of congenital lesions, the odds of MRI detecting the lesions was 5.6 times that of CT. Kappa value was 0 , which meant the agreement between the findings of CT and MRI was poor. In the analysis of inflammatory lesions, the odds of CT detecting lesions was 6.9 times that of MRI. Kappa value was 0.138 , which meant the agreement between the findings of CT and MRI was poor. In the analysis of neoplastic lesions, the odds of MRI detecting lesions was 22.8 times that of CT. Kappa value was 0, which meant the agreement between the findings of CT and MRI was poor.

\section{CONCLUSION}

MRI was better for imaging of congenital and neoplastic lesions with case detection rate of $100 \%$ and CT was better for imaging of inflammatory lesions with case detection rate of $93 \%$.

\section{KEYWORDS}

Inflammatory, Congenital, Neoplastic, Neck Masses, Odds Ratio.

HOW TO CITE THIS ARTICLE: Rani KV, Vernekar JA, Amate SS. Comparative study of CT and MRI in evaluation of suprahyoid neck masses. J. Evolution Med. Dent. Sci. 2016;5(84):6276-6281, DOI: 10.14260/Jemds/2016/1418

\section{BACKGROUND}

The suprahyoid neck masses have proven to be diagnostic dilemma to the radiologists due to complex anatomy of the region and overlapping imaging characteristics. Conventional imaging techniques like plain $\mathrm{x}$-rays have failed to delineate the extent of disease process and substantiate accurate diagnosis. Ultrasonography has difficulty in assessment of deep soft tissue, bony invasion, perineural spread and involvement of skull base. These limitations have paved way for modern cross-sectional imaging techniques like CT and MRI. CT is more sensitive to calcifications, better in depiction of fine bone detail and is relatively free of the effects of degradation caused by motion and other artefacts.

Financial or Other, Competing Interest: None.

Submission 14-09-2016, Peer Review 09-10-2016,

Acceptance 15-10-2016, Published 20-10-2016.

Corresponding Author:

Dr. Jeevan A. Vernekar,

Professor and HOD

Department of Radiology,

Goa Medical College,

Bambolim-403202,

Goa, India.

E-mail: jeevanvernekar11@gmail.com

DOI: $10.14260 /$ jemds $/ 2016 / 1418$
MRI has major strengths in its current conventional use namely excellent soft tissue contrast, multiplanar capabilities, non-invasiveness and lack of harmful radiation. The dilemma therefore for radiologists is to decide whether the additional information provided by the MRI compared to CT always justifies the difference in the cost. Development and advances in CT and MRI have substantially altered the treatment and management of suprahyoid neck masses. Modern crosssectional imaging have improved the accuracy in diagnosis, pre-operative staging and post-op followup.(1) We have made a humble attempt in our study to compare CT and MRI in the evaluation of suprahyoid neck masses.

\section{MATERIALS AND METHODS}

The prospective hospital-based study was carried out on hundred cases in Department of Radiology, Goa Medical College and Hospital from October 2013 to October 2015. Ethical Clearance for the study was obtained before commencement of the study from Institutional Ethics Committee, Goa Medical College, Bambolim, Goa. After taking proper history, clinical examination and laboratory investigations, the patient is prepared for CT scan. Informed consent of patient/attendant is taken. For IV contrast examination, the patient is kept on empty stomach for four to six hours prior to the scan. For CT imaging, patients were scanned in the supine position with the neck mildly 
hyperextended, so that the hard palate is roughly perpendicular to the table. When possible patient is scanned with quiet breathing and swallowing suspended. CT scanning was performed on Siemens definition AS 128 Slice scanner while MRI was performed on Siemens Magnetom Avanto $1.5 \mathrm{~T}$. An informed written consent is obtained from the patient. Patient is asked to remove all metallic objects, undress and change into hospital gown. Patient's height and weight is noted. Contrast injection risks and benefits are explained to the patient. Gadolinium was given only if creatinine was $<1.4$ $\mathrm{mg} / \mathrm{dL}$. Patient is instructed to keep still and avoid swallowing Standard MRI sequences were used and this includes T2 STIR Coronal ( $4 \mathrm{~mm}$ slice thickness), T2WI axial ( $3 \mathrm{~mm}$ ), T1WI axial (3 mm), T1WI sagittal (3 mm), Post contrast T1WI Fat Sat (3 $\mathrm{mm}$ ) in coronal, axial and sagittal planes and Diffusion Weighted Imaging (DWI).

\section{RESULTS}

\begin{tabular}{|c|c|c|}
\hline Sl. No. & Pathology & No. of Cases \\
\hline 1 & Ectopic thymus (Fig. 1) & 1 \\
\hline 2 & 1 st Branchial cleft cyst & 1 \\
\hline 3 & Vascular malformations & 10 \\
\hline 4 & Thyroglossal duct cyst & 1 \\
\hline 5 & Vallecular cyst (Fig. 3) & 3 \\
\hline 6 & Lingual thyroid (Fig. 2) & 2 \\
\hline \multicolumn{3}{|c|}{ Table 1. Distribution of Congenital Lesions } \\
\hline
\end{tabular}

\begin{tabular}{|c|c|c|}
\hline & Detected & Not Clearly Detected \\
\hline MRI & 18 & 0 \\
\hline CT & 16 & 2 \\
\hline \multicolumn{3}{|c|}{ Table 2. Congenital Lesions } \\
\hline
\end{tabular}

MRI detected $100 \%$ cases and CT detected $88.8 \%$ of cases. Odds ratio is 5.6 , that is MRI is 5.6 times more likely to detect congenital lesions compared to CT Kappa value is 0 , which means the agreement between the findings of CT and MRI is poor.

\begin{tabular}{|c|c|c|}
\hline Sl. No. & Pathology & No. of Cases \\
\hline 1 & Ludwig angina & 4 \\
\hline 2 & Cellulitis & 3 \\
\hline 3 & Sialadenitis (Fig. 10) & 11 \\
\hline 4 & Retropharyngeal abscess (Fig. 9) & 2 \\
\hline 5 & Prevertebral space abscess & 1 \\
\hline 6 & Ranula & 3 \\
\hline 7 & Pseudoaneurysm & 1 \\
\hline 8 & Infected haematoma & 1 \\
\hline 9 & Tuberculous lymphadenopathy & 1 \\
\hline 10 & Suppurative lymph nodes (Fig.11) & 1 \\
\hline \multicolumn{2}{|c|}{ Table 3. Distribution of Inflammatory Lesions } \\
\hline
\end{tabular}

\begin{tabular}{|c|c|c|}
\hline & Detected & Not Clearly Detected/Not Feasible \\
\hline CT & 26 & 2 \\
\hline MR & 17 & 11 \\
\hline \multicolumn{3}{|c|}{ Table 4. Inflammatory Lesions } \\
\hline
\end{tabular}

CT detected $92.8 \%$ cases and MR detected $60.7 \%$ cases. In $39.3 \%$ cases, findings crucial for diagnosis and management which were detected by CT could not be demonstrated by MR. Odds ratio is 6.9, that is CT is 6.97 times more likely to detect inflammatory lesions compared to MRI. Kappa value is -0.138 , which means the agreement between the findings of CT and MRI is poor.

\begin{tabular}{|c|c|c|}
\hline $\begin{array}{c}\text { Sl. } \\
\text { No. }\end{array}$ & Pathology & $\begin{array}{c}\text { No. of } \\
\text { Cases }\end{array}$ \\
\hline 1 & $\begin{array}{c}\text { Salivary gland tumours (Fig. 4, 5 \& } \\
\text { 6) }\end{array}$ & 30 \\
\hline 2 & Vagal schwannoma (Fig. 7) & 2 \\
\hline 3 & $\begin{array}{c}\text { Carotid body paragangliomas } \\
\text { (Fig.8) }\end{array}$ & 2 \\
\hline 4 & Carcinoma tongue & 12 \\
\hline 5 & Vallecular carcinoma & 2 \\
\hline 6 & Schwannoma of sublingual space & 1 \\
\hline 7 & $\begin{array}{c}\text { Lymphoma of pharyngeal mucosal } \\
\text { space }\end{array}$ & 2 \\
\hline 8 & Lipoma & 3 \\
\hline \multicolumn{2}{|c|}{ Table 5. Distribution of Neoplastic Lesions } \\
\hline \multicolumn{2}{|c|}{} \\
\hline
\end{tabular}

\begin{tabular}{|c|c|c|}
\hline & Detected & Not Clearly Detected \\
\hline MR & 54 & 0 \\
\hline CT & 45 & 9 \\
\hline \multicolumn{3}{|c|}{ Table 6. Neoplastic Lesions } \\
\hline
\end{tabular}

MRI detected $100 \%$ cases and CT detected $83.3 \%$ of cases. In $16.7 \%$ of cases, findings crucial for diagnosis and management which were detected by MR could not be demonstrated by CT. Odds ratio is 22.8 , that is MR is 22.7 times more likely to detect neoplastic lesions compared to CT. Kappa value is 0 , which means the agreement between the findings of CT and MRI is poor.

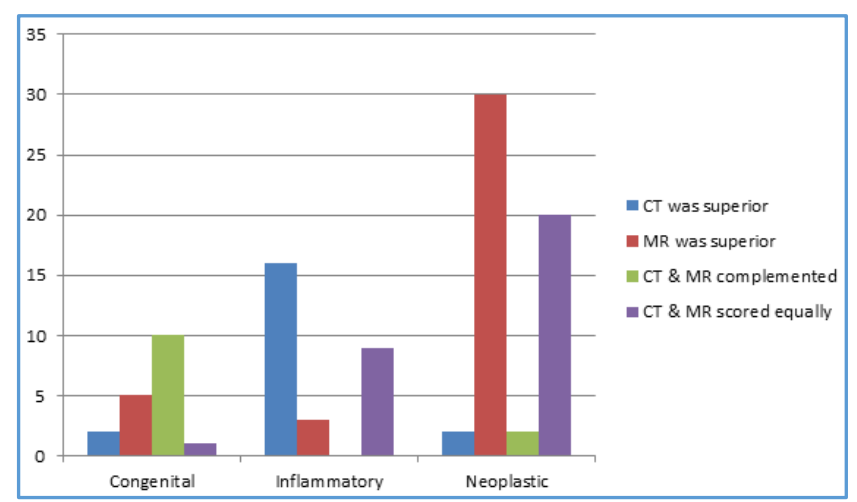

Evaluation of the role of CT and MRI in the imaging of various pathologies of the neck.

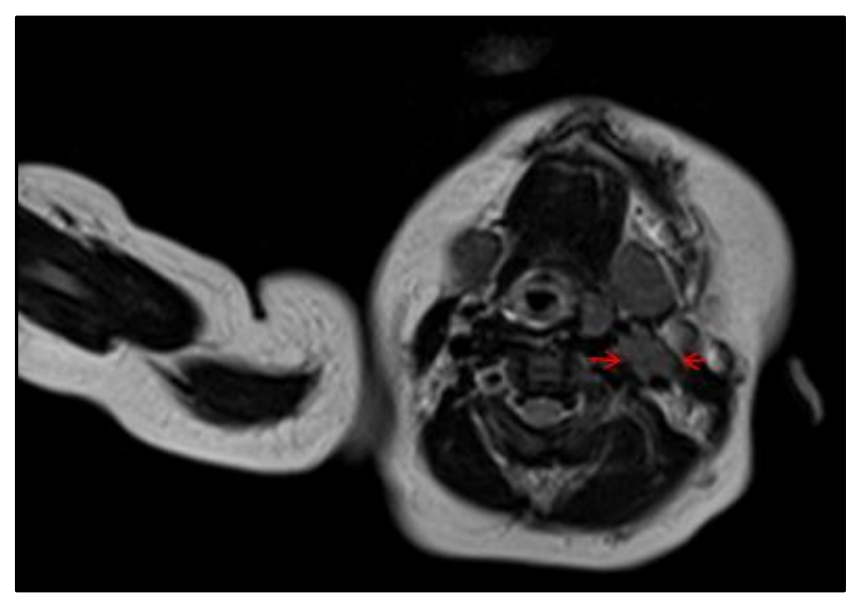

Figure 1. T2WI Sequence shows a Soft Tissue of Intermediate Signal Intensity in the Carotid Space on the Left Side Splaying the Carotid Artery and the Jugular Vein [Ectopic Thymus] 


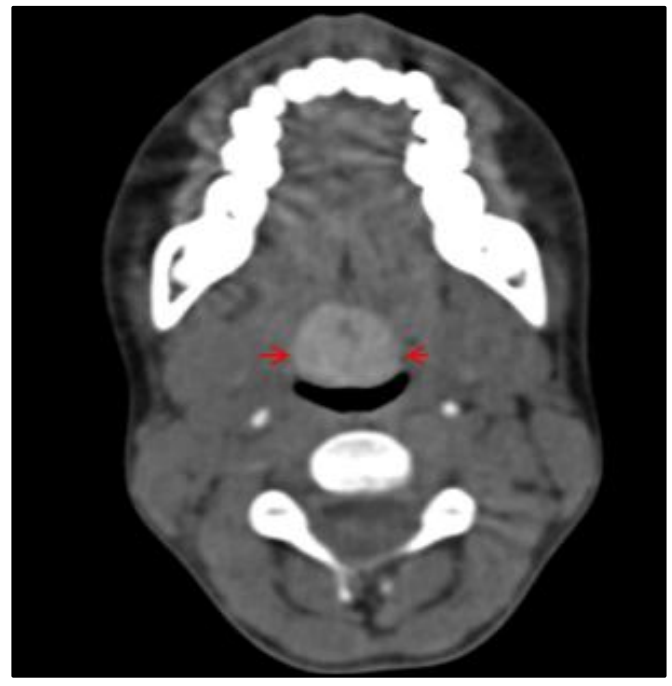

Figure 2. Shows Well-Defined Midline Base of the Tongue Mass showing High Density on Unenhanced CT Scan [Lingual Thyroid]

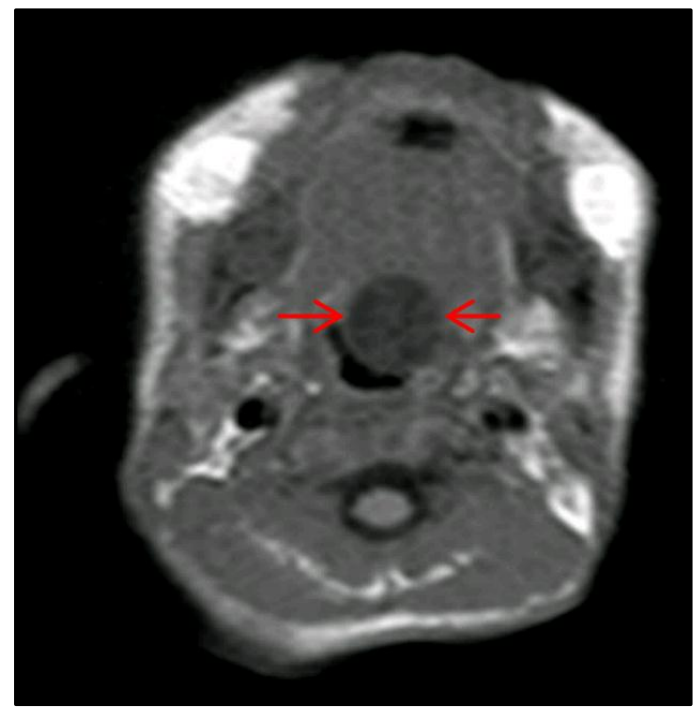

Figure 3. Axial T1WI MR Sequence shows a well defined Hypointense Lesion in the region of Vallecula (vallecular cyst)

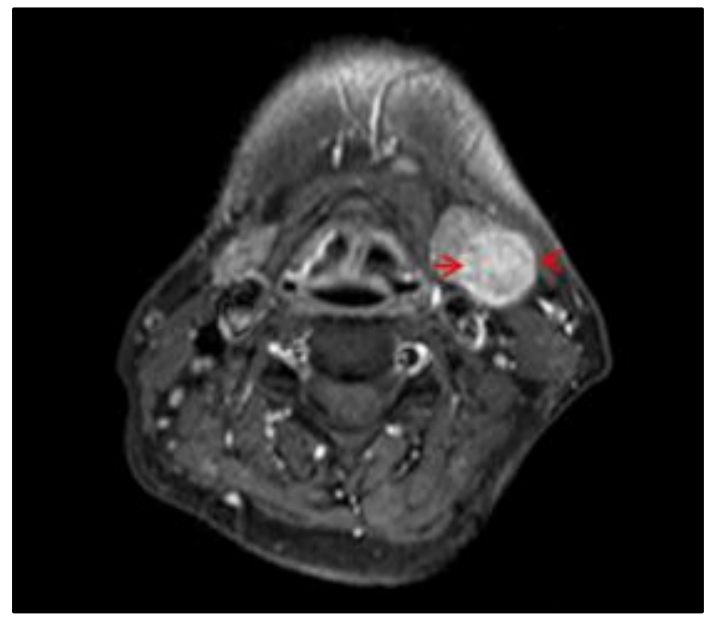

Figure 4. Post Contrast T1 WI Sequence shows an Enhancing Mass in Left Submandibular Gland [Pleomorphic Adenoma]

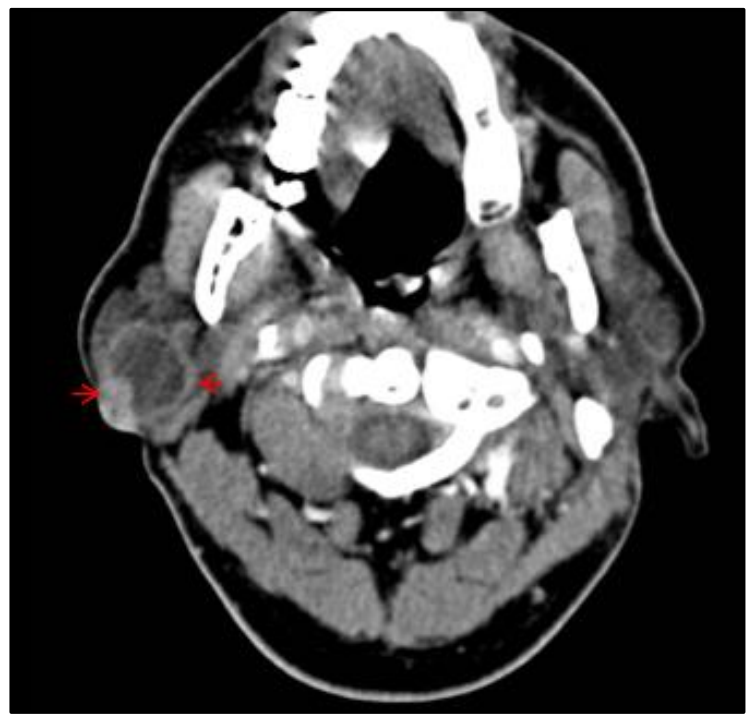

Figure 5. CECT shows a Cystic Lesion with an Enhancing Mural Nodule in the Right Parotid Gland [Warthin's Tumour]
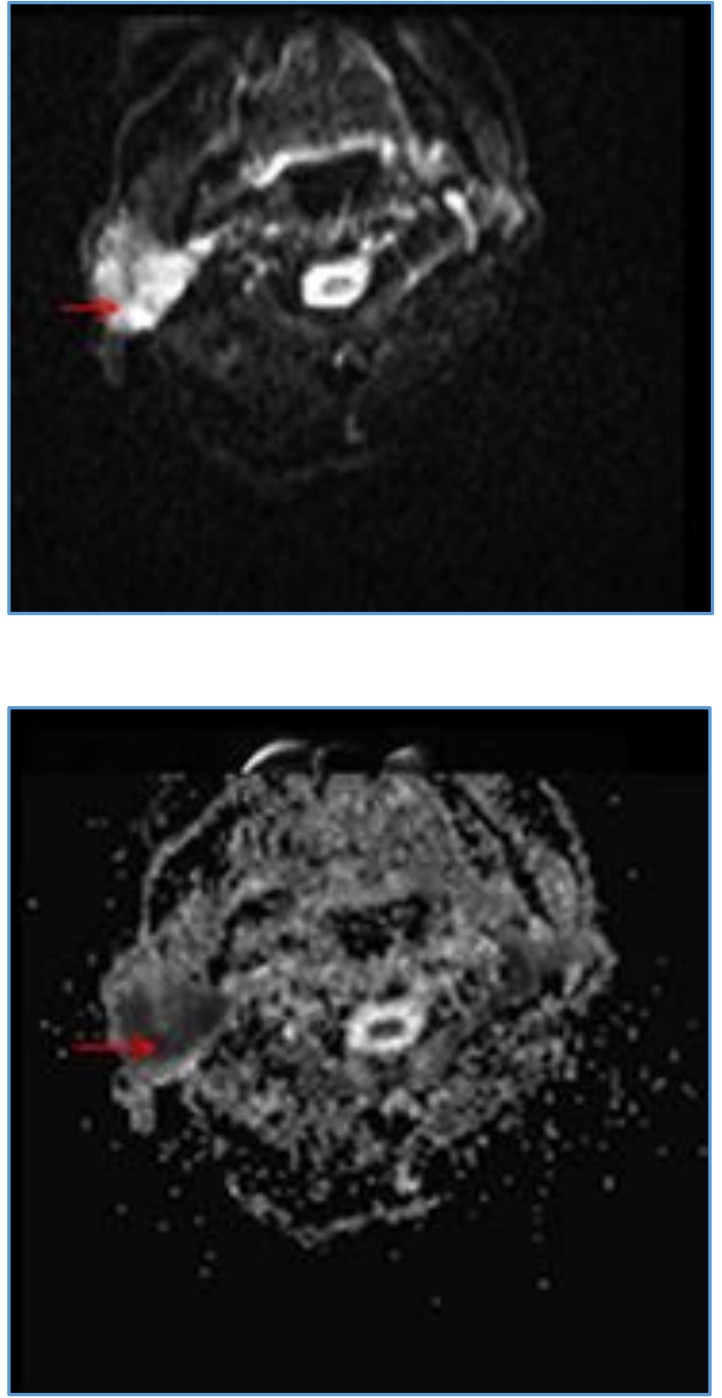

Figure 6. On DWI and ADC Mapping Sequences of the Lesion in the Right Parotid Gland shows Restricted Diffusivity Suggesting its High Cellularity. [Primary Nodal Non-Hodgkin's Lymphoma] 


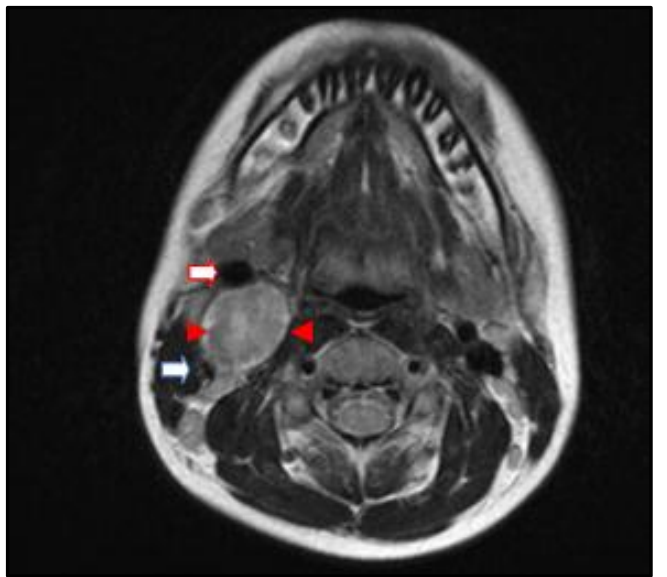

Figure 7. T2 WI Sequence shows a Heterogeneous Mass Lesion in the Carotid Space on the Right Side Displacing the Carotid Artery (Double Red Arrow) Anterolaterally and the Internal Jugular Vein (Double Blue Arrow) posterolaterally. [Vagal Schwannoma]

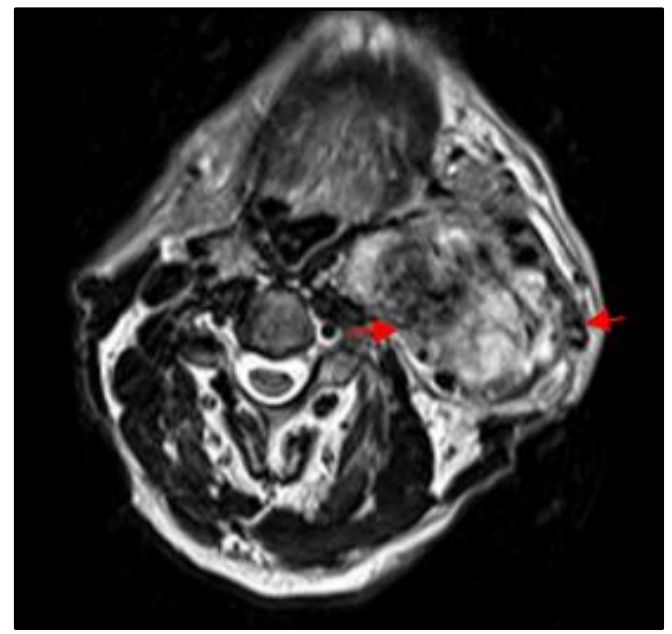

Figure 8. T2 WI Sequence shows Salt and Pepper Appearance of a Paraganglioma in the Left Carotid Space due to Haemorrhage and Arterial Flow Voids. [Carotid Body Paraganglioma]

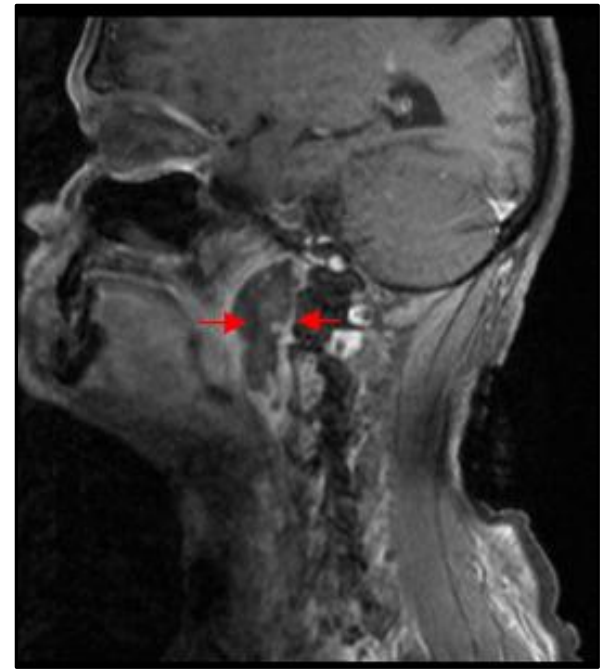

Figure 9. Post Contrast T1WI Sequence shows a Peripherally Enhancing Collection in the Retropharyngeal Space. [Retropharyngeal Abscess]

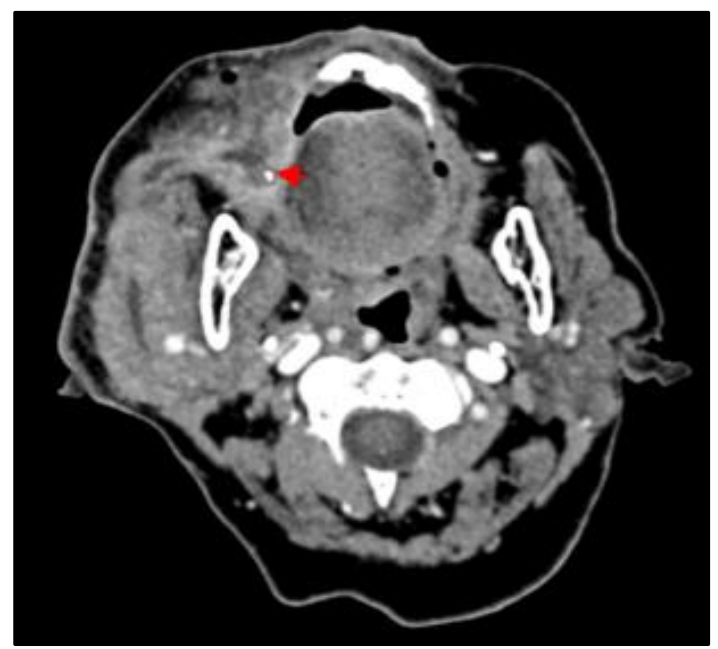

Figure 10. CECT shows a Calculus (Arrow) Obstructing the Stensen's Duct on the Right Side with Associated Parotitis. [Sialocele]

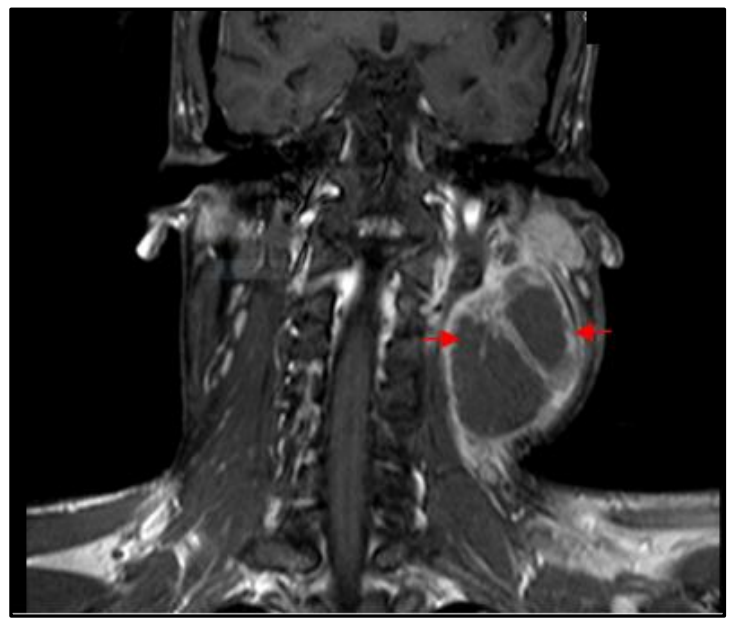

Figure 11. Post Contrast T1 WI Sequence show Large Peripherally Enhancing Lymph Node along the Upper Jugular Chain on the Left Side with Inflammation of the Surrounding Soft Tissue [Nodal Abscess]

\section{DISCUSSION}

A total of hundred patients were studied using CT/MRI or combination of the two modalities depending upon the requirement. Final diagnosis was reached in consensus with pre/post-op histopathology wherever appropriate or clinical; laboratory and other imaging modality findings and long-term follow-up in some of the patients.

\section{Congenital Lesions}

An ectopic thymus and a small branchial cleft cyst in the parotid gland which were studied were barely visible on CT, hence required MRI for complete assessment. CT could define the deep extent of the lesion, help demonstrate phleboliths and fatty components of the vascular malformations studied, but MRI was ultimately required for accurate assessment of their extent and haemodynamics. Similar findings on MRI have been described by Lucia Flors et al.(2) Cases of thyroglossal duct and vallecular cysts could be diagnosed by CT as well as MR. However, MR allowed distinction of a thyroglossal cyst in the foramen caecum from a vallecular cyst, which is a retention cyst on the mucosal margins. Similar findings were described 
by A Lo Casto et al.(3) Cases of lingual thyroid studied showed high attenuation resembling thyroid tissue on CT and therefore could be diagnosed with certainty. Thyroid tissue was not distinctly identified on MRI. Similar findings were described by Arekapudi SR et al(4) [Table 1 and 2].

\section{Inflammatory Lesions}

CT provided the information necessary for emergency management, faster in cases of Ludwig's angina with airway compromise.(5) In addition, theoretically considering gas collections which are so easily distinguishable on CT would have appeared as non-specific signal voids on all the pulse sequences of MR making the diagnosis difficult. In a case of post-traumatic osteomyelitis of temporal bone with associated rim enhancing collections in the masticator space, CT best demonstrated the irregular and sclerosed bone in osteomyelitis. Intraosseous abscess in a case of periapical abscess with myositis, which had tunnelled through the mandibular ramus was also better demonstrated on CT.(6) Calculi in cases of sialadenitis, which were evident on CT(7) were seen as nonspecific signal voids on MR. In a case of intraparotid abscess secondary to acute otomastoiditis temporal bone CT defined the bony changes and CECT the infectious complications. CT and MR demonstrated similar findings in cases of granulomatous and non-granulomatous infections of the parotid gland. In cases of Sjogren's syndrome of the parotid gland, CT failed to reveal cystic dilatations of the intraglandular ducts which were demonstrated by MRI along with lipid infiltration and gland enlargement. Similar findings were described by Izumi M et al.(8) On both CECT and MRI rim enhancing collections and craniocaudal extent of retropharyngeal abscesses was shown and distinction from perivertebral space abscess was made. However, MRI is rarely utilised in haemodynamically unstable septic patients.(8) In a case of prevertebral space abscess, CT best demonstrated the bony changes and helped guide aspiration. Uncertainty about the epidural space involvement had to be cleared by MR. Similar findings were described by Roberto Maroldi MD et al.(9) In cases of ranula CECT and MR, both could define the extent. CT angiography with a shorter acquisition time and ability to detect associated injuries scored over MR in a case of posttraumatic pseudoaneurysm of the superficial temporal artery. Subcutaneous manifestations of infection on MRI were not as obvious as in CT in a case of suppurative lymph node. CECT allowed differentiation of reactive from suppurative nodes, determination of nodal extent and helped carefully evaluate primary source of infection or malignancy. Similar findings were described by Alfred L. Weber et al(10) [Table 3 and 4].

\section{Neoplastic Lesions}

Among the cases of benign mixed tumours and their recurrences post-parotidectomy that were studied by CT and MR the lesion per se and extension to deep lobe was not clearly seen on CECT. In a case of benign mixed tumour of the deep lobe of parotid gland which was not accessible for biopsy, hyperintensity on T2WI sequence of MR helped in suggesting the benign nature of the lesion. In cases of Warthin's tumours, CT and MR both provided adequate pre-surgical information but MR was useful for assessing the accurate extent of malignant tumours of the parotid gland.(11,12) Subtle erosion of the mandibular cortex in one of the cases was better demonstrated on CT. CT only showed diffusely enlarged gland in case of lymphomas and metastases to parotid gland from small cell carcinoma of the lung. On MR performed, subsequently well-defined lesions of intermediate signal intensity showing mild homogeneous enhancement and restriction on DW1-ADC mapping sequences were detected. Similar findings were described in the imaging of salivary gland tumours by A. Christe et al.(13) CT and MR both demonstrated the relationship of mass to carotid artery and IJV in cases of vagal schwannoma and carotid body paraganglioma. Ultimately, the arterial velocity flow voids on T2W1 sequence helped confirm paragangliomas. Similar findings were described by Ibeh and Potigailo.(14) In cases of carcinoma of tongue, vallecular carcinoma and schwannoma of sublingual space, MRI with its better soft tissue definition was the imaging modality of choice. In one case of carcinoma of the tongue, mandibular erosion was better demonstrated on CT. CT was better in staging of cases of nasopharyngeal NHL and Burkitt's lymphoma of the pharyngeal mucosal space. Because of its high cellularity lymphoma shows restriction on diffusion weighted imaging. Similar findings were described by Kind AD et al.(15) In cases of lipoma, both CT and MR scored equally [Table 5 and 6].

Recent advances in evaluation of suprahyoid neck masses include Dual-Energy CT (DECT), MR perfusion and MR spectroscopy. Dual-energy scanning is a breakthrough in CT technology. DECT also has potential in suprahyoid neck imaging. Benefits of DECT include material specific dataset (differentiation of calcification from iodine), improved image quality, better lesion detection and quantitative calculation of the degree of enhancement. Further research is required to make the most of such new technology.(16) Dynamic ContrastEnhanced (DCE) MR perfusion imaging is a non-invasive imaging technique that helps in differentiation of benign from malignant tumours and malignant tumour from post radiation changes. $(17,18)$ High tumour perfusion early during the course of therapy predicts a good response to radiation therapy. This phenomenon may be related to reoxygenation of the tumour early during radiotherapy.(19) MR spectroscopy could be used as complementary method to routine MRI to differentiate between benign and malignant lesions. Mean value of $\mathrm{Cho} / \mathrm{Cr}$ ratio is 4.42 for malignant tumours and 1.93 for benign tumours on Hydrogen $\left({ }^{1} \mathrm{H}\right)$ MR spectroscopy with echo time $270 \mathrm{~ms}$ at 1.5 T.(20)

\section{Limitations}

Biopsy or histopathological diagnosis was not possible in all cases. Some cases diagnosed based on imaging, clinical, laboratory parameters and long-term followup. MR perfusion and MR spectroscopy was not a part of the study, which would have enhanced further tissue characterisation.

\section{CONCLUSIONS}

MRI, because of its multiplanar ability, better soft tissue resolution and lack of ionising radiation, is imaging modality of choice for evaluation of suprahyoid congenital and neoplastic lesions. CT, because of its ability to accurately identify calcification and air foci, is imaging modality of choice for inflammatory lesions in suprahyoid neck spaces.

\section{ACKNOWLEDGEMENT}

We are thankful to Department of Radiology, Goa Medical College, for all the help in carrying out this study. 


\section{REFERENCES}

1. Wippold FJ. Head and neck Imaging: the role of CT and MRI. Journal of Magnetic Resonance Imaging 2007;25(3): 453-65.

2. Flors L, Leiva-Salinas C, Maged IM, et al. MR imaging of soft tissue vascular malformations: diagnosis classification and therapy follow up. Radiographics 2011;31(5):1321-40.

3. Casto AL, Papia G, Purpura P, et al. CT and MRI of thyroglossal duct cyst. ECR Poster No: C1349. http://dx.doi.org/10.1594/ ecr2015/C-1349

4. Arekapudi SR, Vama DR. Lingual thyroid. Pediatr Radiol 2007;37(9):940.

5. Smoker WRK. The oral cavity. In: Som PM, Curtin HD, eds. Head and neck imaging. $4^{\text {th }}$ edn. St. Louis, Mo: Mosby 2003: 1377-1464.

6. Harnesberger HR. Masticator space abscess. In: Osborn AG. edr. Diagnostic imaging head and neck. 1 st edn. Friesens Altona, Manitoba, Canada: Amirsys 2004 P. III 6 12-15.

7. Bailey BJ, Jonson JT, Newlands SD. Head and neck surgery: otolaryngology. $4^{\text {th }}$ edn. Philadelphia, Pa: Lippincott Williams \& Wilkins 2006:1348-53.

8. Izumi M, Eguchi K, Ohki M, et al. MR imaging of the parotid gland in Sjogren's syndrome: a proposal for new diagnostic criteria. AJR Am J Roentgenol 1996;166(6):1483-7.

9. Maroldi R, Farina D, Ravanelli M, et al. Emergency imaging assessment of deep neck space infections. Semin Ultrasound CT MR 2012;33(5):432-42.

10. Weber AL, Siciliano A. CT \& MR imaging evaluation of neck infections with clinical correlations. Journal Radiologic Clinics of North Am 2000;38(5):941-68.

11. Parker GD, Harnsberger HR. Clinical-radiologic issues in perineural tumor spread of malignant diseases of the extra cranial head and neck. Radiographics 1991;11(3):383-99.
12. Barakos JA, Dillon WP, Chem WM. Orbit, skull base and pharynx: contrast-enhanced fat suppression MR imaging. Radiology 1991;179(1):191-8.

13. Christe A, Waldherr C, Hallett R, et al. MR imaging of parotid tumors: typical lesion characteristics in MR imaging improve discrimination between benign and malignant disease. AJNR Am J Neuroradiol 2011;32(7):1202-7.

14. Ibeh C, Potigailo V. Enhancing carotid space mass. Case report. J Am Osteopath Coll Radiol 2015;4(3):24-6.

15. King AD, Lei KL, Richards PS, et al. Non-Hodkin's lymphoma of the nasopharynx: CT \& MR imaging. Clin Radiol 2003;58(8):621-5.

16. Vogl TJ, Schulz B, Bauer RW, et al. Dual-energy CT applications in head and neck imaging. AJR Am J Roentgenol 2012;199(Suppl 5):S34-S9.

17. Razek AA, Elsorogy LG, Soliman NY, et al. Dynamic susceptibility contrast perfusion MR imaging in distinguishing malignant from benign head and neck tumors: a pilot study. Eur J Radiol 2011;77(1):73-9.

18. Furukawa M, Parvathaneni U, Maravilla K, et al. Dynamic contrast-enhanced MR perfusion imaging of head and neck tumors at 3 Tesla. Head Neck 2013;35(7):923-9.

19. Takahashi T, Honda N, Honsono M, et al. MRI perfusion study in head and neck cancers for early prediction of response to radiotherapy: a preliminary study. Issue: Austral-Asian Journal of Cancer 2006:5(4).

20. Fahmy DM, El-Hawarey G, El-Serougy L, et al. Hydrogen MR spectroscopy of neck masses. The Egyptian Journal of Radiology and Nuclear Medicine 2012;43(3):421-7. http:// dx.doi. org/ 10.1016/j.ejrnm. 2012.04.006 